\title{
TRAUMATIC DISLOCATION OF THE TIBIALIS POSTERIOR TENDON AT THE ANKLE
}

\author{
Report of a Case \\ B. E. Nava, Salamanca, Spain \\ From the Lord Mayor Treloar Orthopaedic Hospital, Alton, Hampshire, England
}

Traumatic forward dislocation of the tibialis posterior tendon at the ankle as an isolated lesion must be very rare. Semiluxation of a flexor profundus tendon in the sole of the foot was mentioned by Monteggia (1814) as happening to himself, but from his description of acute pain in the sole of the foot on weight bearing, it does not seem to be the same lesion reported here. The only typical account that I could find in the literature is the one of Martius (1874), who at the age of sixty-seven sustained this injury when he fell off a balloon. He stated that the tendon slipped on the medial aspect of the leg and was mobile under the skin.

\section{CASE REPORT}

A tall boy of sixteen was a passenger in the sidecar of a motorcycle which came off the road at about forty miles per hour, and he was thrown out. While sitting in the sidecar he was on a very low seat with the knees in extension, the ankles in plantar-flexion and the legs laterally rotated with the tread of each foot resting against the bottom end.

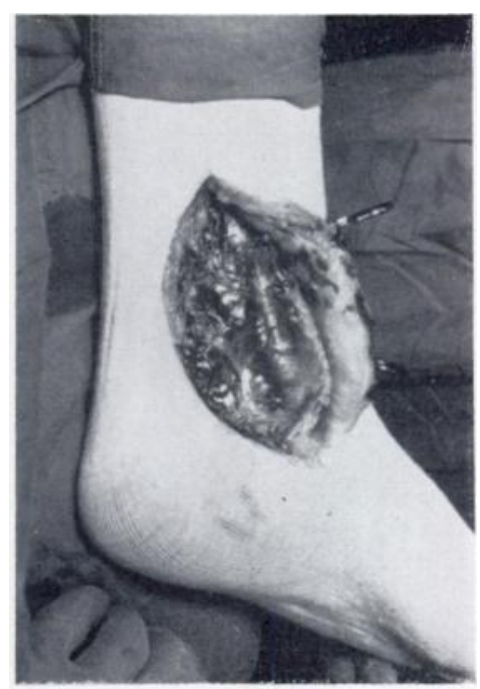

FIG. 1

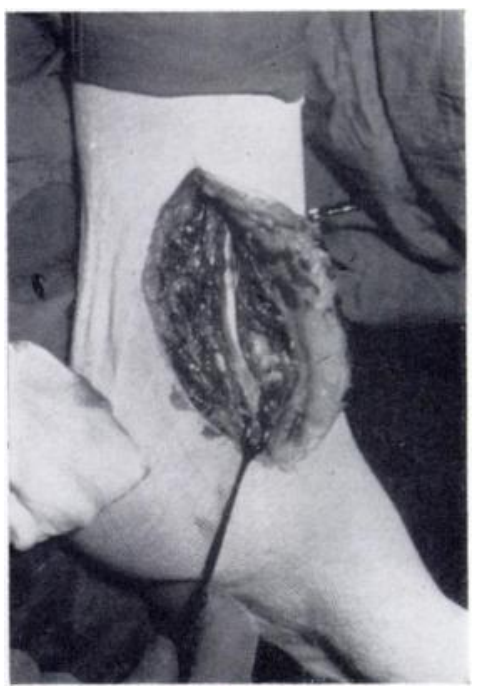

FIG. 2

Figure 1-Showing the tibialis posterior tendon in front of the medial malleolus. Figure 2-Showing the tendon back in place.

When he was admitted to hospital, examination showed a slight swelling of the medial aspect of the left ankle and marked swelling and tenderness over the lateral malleolus of the right ankle. Radiography revealed no bone injury in the left ankle, but in the right ankle there was a transverse fracture (avulsion type) of the lateral malleolus with slight displacement. A below-knee plaster was applied to the right leg and the patient was instructed to walk with crutches. When he tried to stand he felt a sensation of something slipping forward on the medial aspect of the left ankle. Further examination demonstrated increased swelling over 
the medial malleolus and a longitudinal structure could be palpated over it, running obliquely downwards and forwards. Flexion and extension of the ankle were free and painless, but attempts at active inversion were extremely painful. A clinical diagnosis of forward dislocation of the tibialis posterior tendon was made.

Operation-The tibialis posterior tendon was found lying subcutaneously over the medial malleolus (Fig. 1); the groove for the tibialis posterior was empty and the retinaculum was torn. Above, the retinaculum was detached from the anterior lip of the groove, but below it was symmetrically torn. The groove did not appear to be abnormal either in shape or in depth. The tendon was placed back in position (Fig. 2) and the retinaculum was sutured without difficulty. A below-knee plaster was applied for ten weeks. The final anatomical and functional result was excellent.

\section{COMMENT}

The exact mechanism of the injury is unknown, but a probable explanation is that it was caused by forcible dorsiflexion of the ankle in slight inversion counteracted by a sudden pull of the tibialis posterior. The sudden feeling of something slipping forward experienced when the boy first attempted to walk was probably due to forward displacement of an already dislocated tendon. At operation the retinaculum appeared to be of normal size and thickness; no anatomical abnormality could be found in the tibialis posterior groove; no joint laxity or any other predisposing cause could be demonstrated.

\section{SUMMARY}

1. A case of traumatic forward dislocation of the tibialis posterior tendon at the ankle is described.

2. A possible mechanism of the injury is suggested.

I am most grateful to Mr D. E. Macrae for permission to publish this case and to Mr R. W. Small for the photographs.

\section{REFERENCES}

Haberern, J. P. (1902): Ueber Sehnenluxationen. Deutsche Zeitschrift für Chirurgie, 62, 191.

Martius, Ch. (1874): Notes sur un cas de luxation du muscle tibial posterieur, etc. Paris. Quoted by Haberern, J. P. (1902).

MontegGiA, G. B. (1814): Istituzioni Chirurgiche. Edizione seconda, V, 181. Milano: Maspero e Buocher. 